\title{
2011 Census Field design: getting the numbers right
}

Neil Townsend

Office for National Statistics

\begin{abstract}
A labour force of over 30,000 temporary field staff has been employed to carry out the Census. This article summarises the role of the field staff in collecting census questionnaires from households and communal establishments for the March 2011 enumeration. Building on the lessons learned from the 2001 Census, and taking account of changes in society and technology since 2001 , the article provides a summary of the planned field staff structures and processes intended to deal with returned questionnaires and non-responders.
\end{abstract}




\section{Introduction}

This article outlines the design of field staff activities for the 2011 Census in England and Wales. All people who have stayed, or intend to stay, in the UK for a period of three months or more are required to complete a full census questionnaire. The way information is collected will vary depending on the type of property in which people live.

The main division is between people living as a household (including one person households), typically in houses or flats, and those living in some form of managed residential accommodation such as residents of care homes, university halls of residence and army barracks. The former are required to complete a household return. The latter make individual returns co-ordinated by the manager of the Communal Establishment (CE) who is required to complete a brief paper CE questionnaire with details about the establishment. The processes for delivery and collection of questionnaires from households and communal establishments differ.

The design of the 2011 Census field operation for households may be summarised as follows:

- household questionnaires (with questions about the household and up to six residents) delivered by post to households

- the public will respond either on paper by posting back their completed questionnaire, or by making an online return

- 10 days after census day, non-response follow up will commence. Households that are yet to make a return will be visited by field staff to assist them

- questionnaires must be returned or households will be subject to non-compliance

- 'dummy' forms will be created for addresses where no questionnaire has been returned

For communal establishments (CEs) the process will be:

- questionnaires delivered by census staff

- residents will either complete an individual questionnaire (with questions about one person only) and return it to the CE manager or make a return online

- the CE manager will complete a CE questionnaire

- all the paper questionnaires will be collected by a member of census staff for return to the processing centre

- 'dummy' forms will be completed where no return is made

The 2011 Census is an address register based census. An address register has been produced for the Census and used to pre-address and individually bar-code all questionnaires, allowing them to be tracked throughout the process from printing through to receipting. This questionnaire tracking will enable the identification of non-responding households for the non-response follow-up operation, and generate management information on the progress of the process. The design is summarised in Figure 1. 


\section{Figure 1 The Census Field Design}

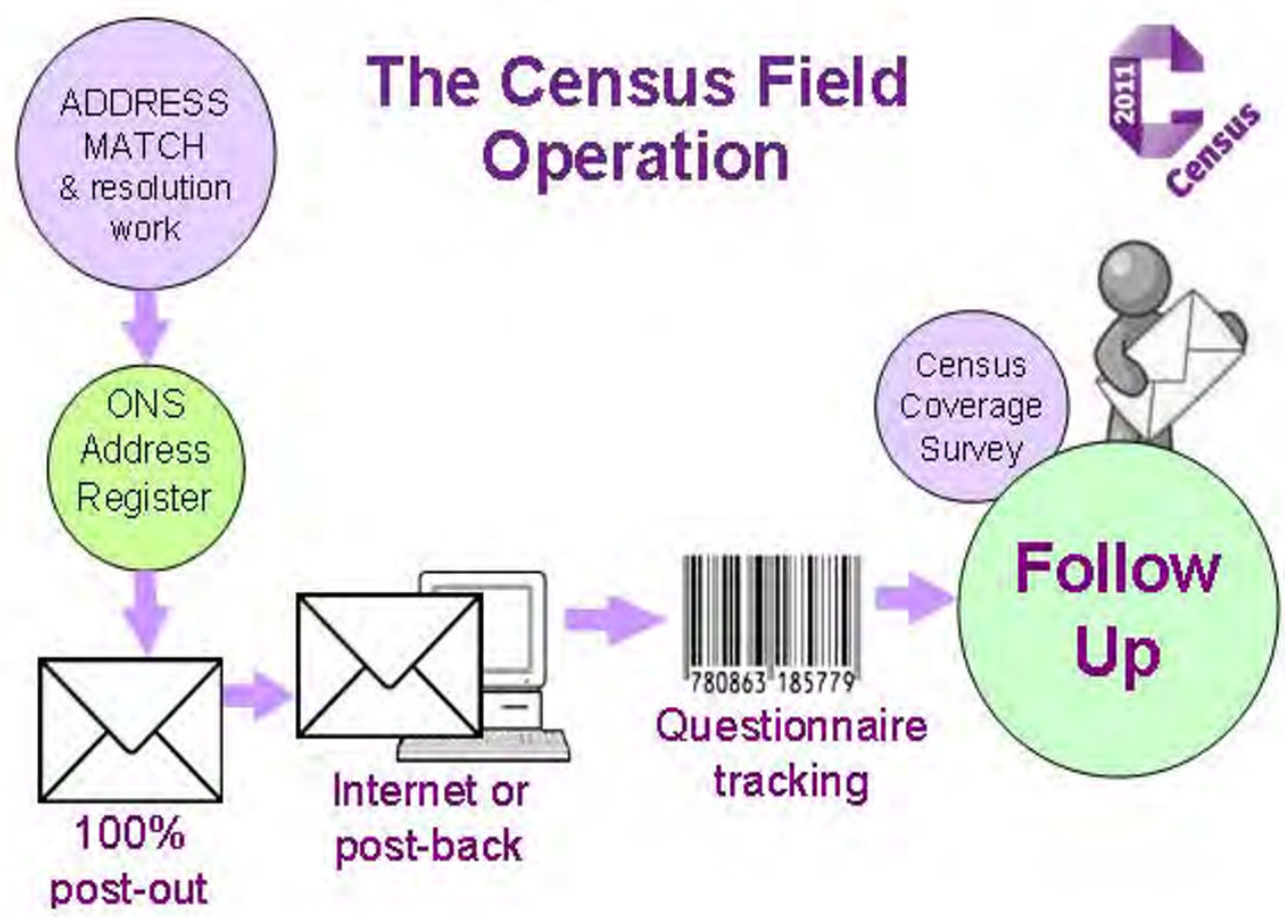

\section{Background to the field force design}

\section{Census}

In 2001, questionnaires were hand delivered by enumerators, but for the first time the public were encouraged to post their completed questionnaires back. Those who did not respond were followed up by enumerators. Although generally successful - the overall response rate was 94 per cent - a number of problems were encountered, the main ones being:

- recruitment of sufficient staff in some areas, especially inner London

- the list of addresses used was significantly out of date and missing some areas of major change

- delays in the postal system

- coverage problems in certain areas; although the overall average was 94 per cent, return rates varied from 68 to 99 per cent at local authority level

- management information was inadequate to identify problems in time to take remedial action

\section{Changes in society and technology since 2001}

Experience shows that it is increasingly difficult to make contact with, and secure a response from, households and this has been a major influence in shaping collection plans for the 2011 Census. These difficulties can be attributed to an ageing population; growing numbers of one-person households; changing work patterns; increase in access security control systems; a less compliant society; growing numbers of migrants; and certain groups and communities within the population feeling increasingly disenfranchised. 
Changes in technology since 2001 offered opportunities to enhance the census collection operation. Predominantly the growth in use of the internet means online completion and assistance is likely to be well used.

\section{Quality goals}

As a result of the factors identified above, the objectives of the 2011 Census are to both maximise the overall return rate and minimise return rate differentials between, and within, local authorities. In addition, it has been designed to minimise recruitment risk and enable operational problems to be identified promptly so that remedial action can be taken.

\section{Field staff}

A labour force of over 30,000 temporary field staff has been employed to carry out the Census (shown in Figure 2 and Table 1). There is a hierarchical management structure to this field force, headed by 157 census area managers employed for about a year from August 2010. These area managers are responsible for liaison with local authorities and community groups, publicity and managing the collection operation in their area.

\section{Figure $2 \quad$ Field Staff Structure}

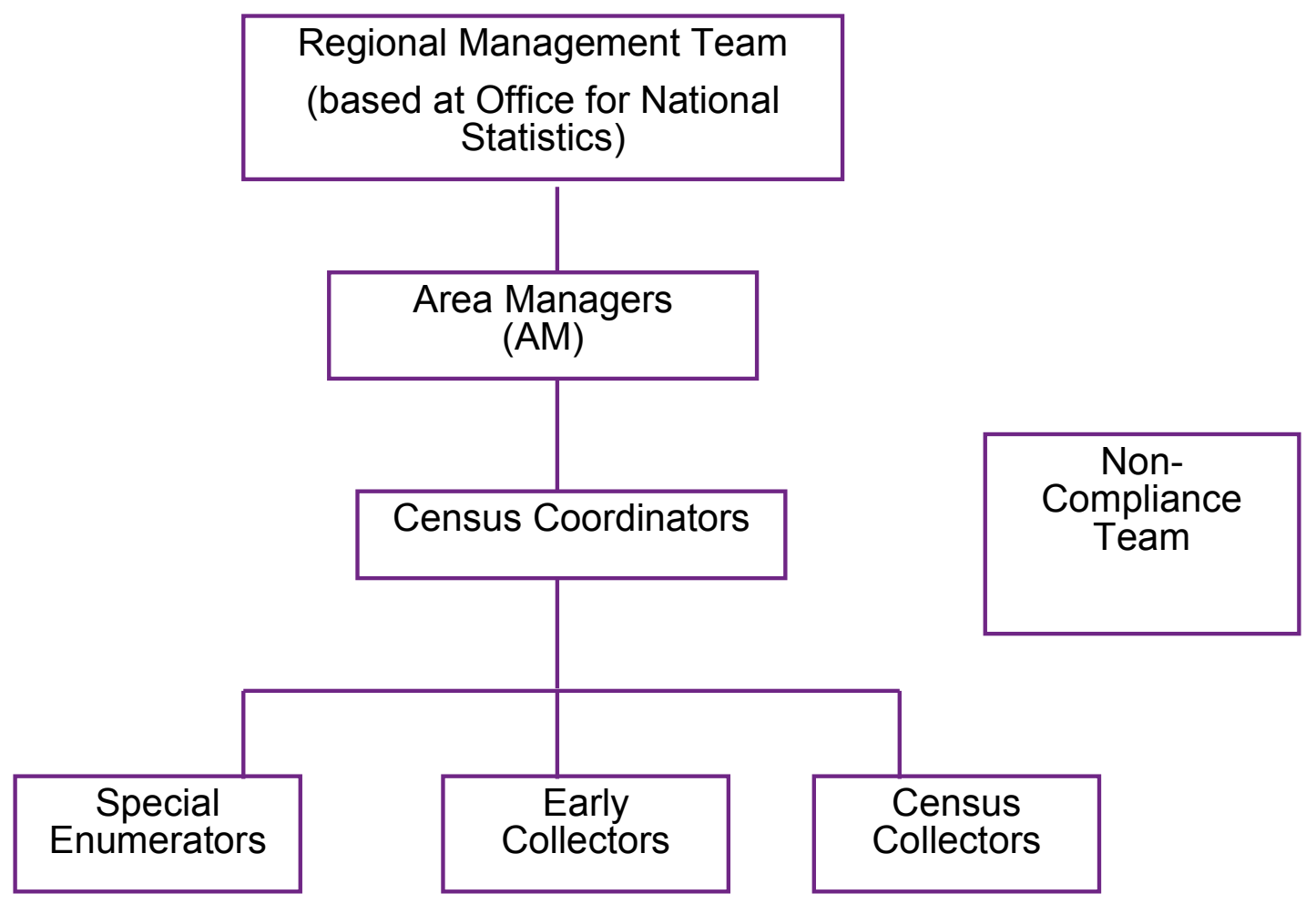

In February 2011 some 2,200 census co-ordinators commenced their roles of managing the operation locally. This includes delivery and collection of questionnaires for communal establishments in their area, and organising the non-response follow up operation. They typically manage a team of $12-15$ staff, mainly collectors. 
There are around 30,000 collectors whose role is to get returns from non-responding households. The majority of these staff will commence their duties 10 days after census day (27 March). In each coordinator area, two 'early collectors' started a week before census day. In their first few weeks, they will concentrate on assisting people to complete questionnaires where special visits are needed, checking the status of addresses where the Royal Mail did not deliver a questionnaire and/or commencing follow up.

\section{Table $1 \quad$ Number of field staff by grade and months employed}

\begin{tabular}{|c|c|c|c|c|c|c|c|c|c|c|c|}
\hline & $\begin{array}{l}\text { Aug- } \\
2010\end{array}$ & $\begin{array}{l}\text { Sept- } \\
2010\end{array}$ & $\begin{array}{l}\text { Oct- } \\
2010\end{array}$ & $\begin{array}{l}\text { Nov- } \\
2010\end{array}$ & $\begin{array}{l}\text { Dec- } \\
2010\end{array}$ & $\begin{array}{l}\text { Jan- } \\
2011\end{array}$ & $\begin{array}{l}\text { Feb- } \\
2011\end{array}$ & $\begin{array}{l}\text { Mar- } \\
20111\end{array}$ & $\begin{array}{l}\text { Apr- } \\
2011\end{array}$ & $\begin{array}{l}\text { May- } \\
2011\end{array}$ & $\begin{array}{l}\text { Jun- } \\
2011\end{array}$ \\
\hline $\begin{array}{l}\text { Area } \\
\text { Managers }\end{array}$ & & & & & & 157 & & I & & & \\
\hline $\begin{array}{l}\text { Census } \\
\text { Coordinators }\end{array}$ & & & & & & & & 194 & & & \\
\hline $\begin{array}{l}\text { Special } \\
\text { Enumerators }\end{array}$ & & & & & & & & 174 & & & \\
\hline $\begin{array}{l}\text { Early } \\
\text { Collectors }\end{array}$ & & & & & & & & & 4388 & & \\
\hline $\begin{array}{l}\text { Census } \\
\text { Collectors }\end{array}$ & & & & & & & & T & 253 & & \\
\hline
\end{tabular}

Census day $(27 / 03 / 2011)$

For the enumeration of CEs and special population groups (for example gypsies and rough sleepers) around 1,700 Special Enumerators have been recruited.

The recruitment, training and payment of this large, temporary census field force has been undertaken by Capita. By outsourcing the recruitment, pay and training of field staff the aim was to:

- minimise recruitment risk (using an organisation with specialist skills, existing systems and national reach) with contractual obligation to deliver required numbers everywhere

- minimise payroll risk of having to pay such a relatively high number of people for a short period of time

- have consistent training across the country delivered by professional trainers

The aim was to recruit staff who reflected the profiles of the communities in which they would be working. Not only was this a necessary stance in terms of ensuring equal opportunities, but it will also enable field staff to engage more effectively with the local communities they are enumerating, encourage participation and understand the support required. This includes, for example, ensuring that sufficient numbers of Welsh-speaking field staff are recruited in Wales.

\section{Questionnaire delivery}

Questionnaires have been posted out to all households in England and Wales. The post out operation began on Monday 7 March 2011, with all households receiving their questionnaires by 
Saturday 19 March 2011. Along with their questionnaire, each household received a prepaid envelope for returning their completed questionnaire and an information leaflet explaining the purpose of the census and why they should complete it.

Households in Wales have received a version of the questionnaire in both English and Welsh, enabling them to choose which language to use to make their census return.

Post-out has been the means of questionnaire delivery to households in all areas. However, special enumerators have delivered questionnaires by hand to CEs.

\section{Making a return}

Two principal response routes are available to enable the public to complete their census return, either:

- completing the paper questionnaire and posting it back, or

- completing a return online. Each questionnaire has a unique internet access code enabling the householder to access the census website securely and complete their return. The online completion option will be available in Welsh and English for Welsh householders

Householders may also hand their questionnaire to a member of census staff at the doorstep.

Paper forms will be returned to the processing site in Manchester for the data to be captured. All questionnaires are uniquely bar-coded and as they pass through the postal system, this bar-code will be read and the information passed to ONS. This will enable ONS to know which households have made a return and, more importantly in the short term, which ones have not.

When the questionnaires are scanned, any identified as blank or partially complete may be subject to follow up.

It is estimated from international census experience that up to 25 per cent of households will respond online - over 5 million responses in England and Wales. However, the actual take up of this channel is uncertain, so planning has allowed for flexibility.

\section{Follow-up}

Through the use of post-out and post back/internet capture, the aim is to count all those people who can make a return with minimal assistance as cost effectively as possible. This then means resources can be targeted at those unwilling, or unable, to make a return without intervention from ONS.

Field staff will carry out the remainder of the follow-up operation. Starting 10 days after census day, collectors will be issued with lists of non-responding households. Their objective will be to obtain a return from each of these households, either by helping them complete the questionnaire (explaining the questions, providing translation or advice) or persuading them to do so if previously unwilling (reminding householders of the compulsory nature of the Census).

This activity will continue for four and a half weeks. This will give time to make repeated visits to households where previously the collector was unable to make contact. To maximise the chances 
of finding people in, collectors will be required to make visits at different times of the day and on different days of the week; 60 per cent of their hours will need to be worked in the evenings or weekends, the times when more people are home.

Follow-up becomes progressively harder as the proportion of difficult to contact and non-compliant households remaining in the pool of outstanding households increases as the number of 'straightforward' households responding promptly are processed. In some areas where high return rates have been achieved, follow-up may be reduced to enable resources to be moved to areas with lower return rates.

To meet the objective of minimising differentials between areas, enumeration districts where return rates are relatively low will be prioritised. The Questionnaire Tracking (QT) system will give up to date information on return rates and give coordinators the information they need to allocate workloads.

In addition to field staff visits, households who have not returned their census questionnaires will be posted a non-response letter.

'Dummy' forms will be created for addresses where no questionnaire has been returned. The dummy form will identify addresses where the household is absent, where no questionnaire was returned and contact could not be made, that are second or holiday addresses, are vacant or where householders have refused to supply census information. Corresponding categories for communal establishments are absent establishments, those that did not return questionnaires and where contact could not be made, vacant communal establishments or those that refused to return questionnaires.

The revised design means the overwhelming majority of the field work is at the non- response follow-up stage. The main driver for resource allocation is the number of initial non-responding households rather than the total number of households in an area. This, and the objective of improving return rates in more difficult areas, means that the distribution of staff is much less uniform than in previous censuses with many more being allocated to 'harder' areas than 'easier' ones.

A field workload allocation model has being used to estimate the amount of follow-up resource required to achieve minimum return rate thresholds. The workload allocation model uses lower super output areas (LSOAs) as a building block. For each LSOA, the model calculates the number of staff needed based on:

- an estimate of how many households will return a questionnaire without intervention

- how successful a collector will be in getting a completed questionnaire from each visit during follow-up

- how long each visit will take given the type of area

The key factors of the model interact to provide an estimate of the required follow-up resource for an area. 


\section{Explanation of model}

\section{Step one - initial return rates}

First - the proportions of census forms returned by day-10 have been calculated based on factors associated with low return rates in 2001. These include variables such as ethnicity, unemployment, age, crime levels, house price changes and housing density.

Second - the final predicted return rates are adjusted to a day-10 return rate (essentially removing the effect of follow-up in 2001). The relationship between day 10 and final household return rates is estimated from the Royal Mail postal return rate data from 2001. This showed that approximately 82 per cent of questionnaires finally returned were actually returned by day 10 , that is, without intervention.

Third - a further adjustment is made to take account of the impact of post out, a design change since 2001. There is no data that allows the impact of this design change to be assessed under census conditions. However, its impact was assessed during the 2007 Census Test and overall postal delivery reduced day- 10 return rates by 0.875 . This factor is used to adjust the day-10 return rates further after the previous day-10 rate is calculated.

\section{Step two - success at follow-up}

Every LSOA has been classified into a hard to count (HTC) category based on the estimate of 2011 return rates described above.

HTC 1 - the top 40 per cent of responding areas

HTC 2 - the next 40 per cent of responding areas

HTC 3 - the next 10 per cent of responding areas

HTC 4 - the next 8 per cent of responding areas

HTC 5 - the last 2 per cent of responding areas

For each HTC the likelihood of getting a questionnaire returned from each follow-up visit has been estimated. These estimates are based on data and experience from other surveys that ONS conducts which clearly show the probability of getting a return reduces after each unsuccessful attempt.

From this, the number of visits required to reach given return rates has been calculated. This was determined by an optimising process that balanced the requirement to reach both a high overall return rate (target of 94 per cent) and a minimum threshold in each local authority (target of 80 per cent minimum).

\section{Step three - determining collector numbers}

The number of hours of follow-up effort needed is calculated by taking the number of visits required in an LSOA and dividing by the number of visits per hour possible. The number of visits per hour varies, depending on the nature of the area: more visits are possible in urban areas (less travel time between addresses and typically lower contact rates) than rural areas, where the opposites apply. These estimates are based on information from the 2007 Test and the 2009 Rehearsal. 
After the amount of hours required was determined, an estimate of the number of collectors required was calculated, based on an assumption that all collectors will work a 25-hour week. In practice collectors will be contracted to work 15, 25 or 35 hours per week.

The workload allocation model estimates how much resource is required based on a number of assumptions. The accuracy of these assumptions will fluctuate more at the lower geographic levels. However, at local authority level these fluctuations are reduced and therefore provide a realistic overall estimate of field resource required for each local authority.

Inevitably, actual day-10 return rates will vary from that estimated in some areas, meaning that there may be too many or too few collectors in an area for the amount of non-responding households. Managing this variation will be a key role of the coordinators and area managers, who will move resource between census coordinator areas and/or authorise allocation of more resource (hours or people) to meet local needs depending on the return rates.

\section{1 field staff resource}

Overall, the number of collectors to be recruited for the 2011 Census for each local authority is nearly three times the resource that was planned for collection and follow-up activities in 2001. Table 2 shows the degree of additional planned resource in 2011, compared to 2001, by HTC.

\section{Table 2 Relative increase in planned resources for 2011 compared to $2001^{1}$}

\begin{tabular}{l|r}
\hline HTC & $\begin{array}{r}\text { Change 2001 } \\
\text { to 2011* }\end{array}$ \\
\hline Overall & 2.8 \\
HTC 1 & 2.5 \\
HTC 2 & 2.6 \\
HTC 3 & 3.1 \\
HTC 4 & 3.2 \\
HTC 5 & 4.1 \\
\hline
\end{tabular}

${ }^{*}$ Relative increase in planned collection hours for 2011 compared to planned enumerator hours on collection/follow-up in 2001

\section{Counting communal establishment residents}

\section{Delivery of questionnaires}

Questionnaires are being delivered by hand to all CEs. For the majority of CEs they are being delivered by Special Enumerators. This group of staff will work solely on CEs and so get tailored training for the specific challenges of enumerating CEs (this also means the collectors working solely on households will need to know little about CE processes - except for being able to identify them).

The delivery operation started on Monday 7 March, three weeks ahead of Census day and lasts up to Census day. Wherever possible, special enumerators have prioritised CEs with more stable 
populations first (for example halls of residence), leaving those with more fluid populations (for example hotels) until closer to 27 March.

\section{Collection of questionnaires}

Questionnaires from CEs will be collected by census staff rather than being posted back. This is for both cost and coverage reasons (the special enumerator can check the questionnaires collected and match them with those they expect to collect). They will receive information on internet returns from the QT system (via their census co-ordinator).

The collection phase will continue until three weeks after Census day. Again, the visits will be scheduled to prioritise those areas where turnover of residents is greatest. Repeat collection visits will be made if needed and extra assistance offered, along with encouragement of residents and managers as necessary. If any questionnaires are outstanding at the end of the field work, post back will be offered. As with households, CE residents will be reminded that the Census is compulsory and that non participants may be prosecuted.

\section{Non compliance}

Inevitably not all households will respond to the Census. Those that refuse to send back a completed questionnaire pass into a non-compliance process. The Census is compulsory and people who refuse to complete the questionnaire may be visited by non-compliance staff. They will offer and encourage the person to comply but ultimately some people will be prosecuted. Noncompliance staff are required to be confident in dealing with difficult situations and have a degree of relevant experience.

\section{Conclusion}

The 2011 Census field design is based on research and experience. It is designed to include flexibility to manoeuvre and respond quickly to situations on the ground, allowing the most effective management of staff to achieve the response rate objectives outlined in this article.

\section{References}

1 Office for National Statistics www.statistics.gov.uk/about/methodology by theme/area classification/downloads/User Guide.pdf 